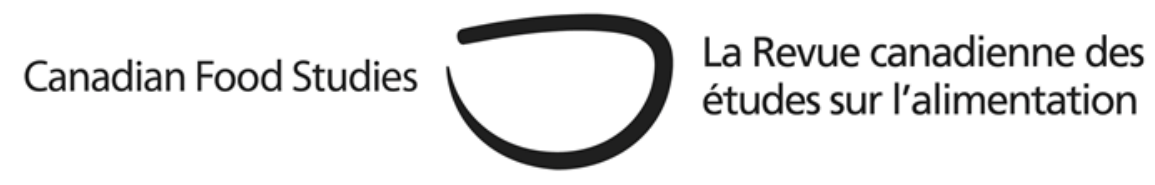

Original Research Article

\title{
Digesting performance: an embodied-environmental approach to food pedagogy
}

David Szanto*

University of Ottawa

\section{Abstract}

Food and food systems are distinct from many other areas of study, in part because of the material, experiential, and affective elements they comprise. Teaching about food can therefore benefit from pedagogical approaches that acknowledge, account for, and activate intersubjectivity, emotions, and relationships to both physical space and food matter. A pedagogy of performance responds to these needs with both theoretical and practical tools, as well as an inherently systems-based perspective and opportunities for experiential, relational, and interdisciplinary learning. This article presents the processes and observed outcomes of an intensive food and performance course taught at Quest University Canada during the fall of 2019. Performing With(in) Food brought together critical discussions of food studies and performance texts, analysis of food-related performances and artworks, bodywork and affect exercises, and practical experience in performance creation. The result was an experiment in mixing discursive and embodied learning that raised and examined complex food issues, activated individual investment in these issues, and brought about student success and transformation.

Keywords: Food pedagogy; embodied learning; performance; trust; risk; transdisciplinarity 
Introduction

"We are, it turns out, not billiard balls but tubes or, if you prefer, donuts..."

—Lisa Heldke (2018, p. 248)

As areas of study, food and food systems are distinct from many others, in part because of the material, experiential, and affective elements they comprise. Compounding this, students who select food-related courses and programs do so for diverse and often very personal reasons. Teaching about these subjects can therefore benefit from approaches that acknowledge, account for, and activate the intersubjective and emotional relationships among food, human beings, and the built and biogeophysical environments. Moreover, because food is characterized by pluralistic forms of knowledge, each of which is constructed in different ways, food pedagogy requires multiple modalities and a variety of paces and contexts.

Performance offers a response to these needs, comprising diverse theoretical and practical tools, as well as a coherent framing of the ways in which theory and practice are themselves codependent. Performance also embeds an inherently systems-based perspective, opportunities for experiential and relational learning, and a critical stance regarding power, all of which are becoming increasingly central to food study (Stephens, 2021). Taken in a broad sense, performance is "a dynamic relationship between action and the environmental conditions of its enactment" (Pearson, 2006, p. 220), one that transcends theatricality to also encompass social, material, and ecological dynamics (Carlson, 2004; Denzin, 2003).

Foodish things perform in many different ways. Seeds germinate and grow into plants, producing fruiting bodies that perform effects within the larger bodies that ingest and digest them. Cooks and eaters perform, enacting gestures and utterances, following and improvising around scripts that are both written and intuitive. Artists perform with and about food, producing visceral-emotional-cognitive effects in their audiences and in the spaces around them. And those in the media, who create language and images to express ideas about cuisine and heritage, can be said to be performing, in part, our gastronomic culture. As Richard Gough has noted, food is "a medium for performance and...a model of performance: multisensory, processural and communal" (1999, p. iii).

Performance can thus be understood as a framework with which to perceive, learn about, interpret, and reflect on any number of food contexts. Whether examining the 'natural' cycles of agricultural production, the restaurant-kitchen enactments of 'culture', the macro- and microbiotic collaboration that is digestion, or the systemic conditions that can actualize community food security, performance-based pedagogy offers tools and insights beyond conventional learning frameworks. In short, performance in the classroom allows the lively bodies of students to come into resonance with the lively bodies (and bodies of knowledge) that constitute food and food systems. 
This article presents the processes and observed outcomes of an intensive, three-and-ahalf week, eighteen-class course, taught at Quest University Canada during autumn 2019. Performing With(in) Food invited students to critically examine and reflect on food studies texts, syntheses of performance theory and practice, and a raft of food-related performances and artworks. A set of course assignments and experimental practices created opportunities for integrated learning, including bodywork exercises, reflexive writing assignments, performative 'field trips' on the university campus, and a final, student-created food-performance showcase.

As the course developer and instructor, I also acted as a participant-researcher, with written consent from the students to document my observations and to collect photographs and video recordings of their final performances. ${ }^{1}$ By engaging the students' entire corpus in learning — including the sensorium, affect, emotionality, and the intellect - I witnessed them find diverse and very personal points of articulation with our coursework. These were eventually expressed through the development and presentation of their performances, which demonstrated complex understandings of their chosen themes as well as their own positionality. Yet the students and I were also met with a series of resistances to learning and teaching through performance, including questions related to trust and consent, the penetration of emotional and intellectual boundaries, disruptions to the spaces around us, and the perceived rigour and legitimacy of performance as a learning and research method.

In what follows, I juxtapose in-class exchanges, reflections on teaching about food and performance, and examples of the students' performance pieces. My aim is to iteratively demonstrate the value of mixing discursive and embodied learning to engage with complex food issues, activate individual implication in food, and bring about student success and transformation.

\section{Performance-based pedagogy}

"Performance and performative thinking can illuminate complex theoretical ideas in new ways and...can become an interdisciplinary foundation for a host of intellectual issues. "

- Sally Harrison-Pepper (1999, p. 141)

A growing body of literature addresses the ways in which embodied learning can enable students to create knowledge not only through intellectual processes but also those associated with making and doing, sensing and reflecting (Evans et al., 2009; Stoltz, 2015).

\footnotetext{
${ }^{1}$ For the purposes of this research, ethics clearance was applied for and received from both Quest University Canada and Carleton University, where I was then engaged as a postdoctoral fellow.
} 
Moreover, within food contexts, 'embodiment' is coming to be understood as a holistic experience of the production of integrated knowledges, in which mind, body, emotion, and affect are all engaged at once and in relation to each other (Heldke, 2006; Lupton, 1996; Perullo, 2016). This interpretation resists classical delimitations of the human corpus and its sense-making processes, and recognizes the wholeness of lived experience and the hybridity of enacting knowledge (Korsmeyer \& Sutton, 2011; Nguyen \& Larson, 2015). It also tends to counter some of the ways in which human understanding itself has been historically categorized-including 'low' and 'high' knowledge, the 'mind-work' of episteme and the 'hand-work' of techne, the 'aesthetics' of art and the 'functionality' of craft. Embodied learning can therefore help students unify and deepen the ways in which they interpret the world, maintain a high level of investment in food issues, and take innovative action towards addressing some of the large-scale, "wicked problems" (Conklin et al., 2011) that characterize many of our realities.

Performance-based pedagogy celebrates and leverages embodiment, offering "a way of knowing... a strategic analytic... a way of seeing and understanding the nuanced nomenclature of human social dynamics" (Alexander, 2006, p. 253). Learning about and through performance engages students' heads, hearts, and hands, giving them "the building blocks to create their own universes, to imagine the ways to take us forward into tomorrow" and to become adept at "dealing with given circumstances [and] engagement with the situation of the moment" (Abrams 2021, pp. 1 - 2). In addition to the immediacy of 'the moment,' performance also leaves and activates space for subsequent feedback and reflection, which helps challenge institutionalized power dynamics and situates students as both empowered and agential (Freire, 1996; Bradley et al., 2018).

Embedded within performance is performativity - the transformational potential emerging from the interaction of distributed agencies (Loxley, 2007; Miller, 2007). These include non-living and non-physical things such as architecture, designed objects, language, emotionality, atmospherics, and space (Carlson, 2004; Fischer-Lichte, 2008; Sweetser, 2001). Performance-based pedagogy thus aligns with a wide range of other learning models that acknowledge relationality, including reinterpretations of networks and systems (Gloor, 2006; Latour, 2013), nature-culture assemblages (Bennett, 2009; Phillips, 2006), the productive 'mess' of post-disciplinarity (Cook, 2009; Law, 2004), social resilience and ecosophy (Folke, 2006; Guattari, 2008; Morton, 2007), Indigenous paradigms (Settee \& Shukla, 2020; Wilson, 2009), and iterative design and 'becomingness' (Akama, 2015; Orr, 2004). While it would be overstating the nature of performance to say that it transects all disciplines, practices, and frameworks, it remains open to connection with numerous currents in contemporary food scholarship.

Performance also embraces improvisation, itself interpreted in multiple ways and, owing to its own nature, resistant to singular definition. Improvisation can be understood as a deviation from a 'script' (either written or implicit), as well as a mutually productive companion to scriptedness (Sawyer, 1999). Improvisation leaves space for and takes advantage of the emergence of unexpected outcomes (Caines \& Heble, 2014; Hallam \& Ingold, 2007; Sawyer, 
2004), serving as "a necessary experimentation with context, but also a specific practice, an awareness of playing the potential and possibility of any moment with the tools at hand" (Fischlin \& Porter, 2017, p. 4). In both the field and the classroom, therefore, improvisation can enable students and teachers to develop alternative understandings of the food systems, cultures, and ecologies they collectively examine. Practically, it empowers students to customize their classroom experience while helping teachers respond to a diverse array of learning habits.

At the same time, and for many of the same reasons, performance-based pedagogy can be destabilizing for learners and teachers. The 'non-definitions' at the foundations of both scripted and improvised performance can trouble conventional learning habits, particularly among students whose previous educational experience has taken place within more positivist framings. This can disrupt classroom patterns and introduce doubt and discomfort. It also presents challenges when it comes to course design, including learning goals and modes of evaluation. The "alternative social spaces of engagement and resistance" (Fischlin \& Heble, 2004, p. 2) offered up by improvisation and performance tend to cut both ways.

To address these destabilizations, a high level of trust needs to be built in to the processes and objectives of performance-based learning. McRae \& Huber (2017) propose the use of "warm-ups" within learning, including sensory and bodily mindfulness exercises that ground a classroom group in a shared experience and moves them toward commonality, and therefore, trust. Following Pineau (1995), they highlight "everyday performances as invaluable sites of knowledge and learning" (McRae \& Huber, 2017, p. 165), ones that relate reassuring and familiar acts — such as shopping, cooking, and eating — to the more risk-infused spaces of postsecondary education.

More explicitly, Aidan Curzon-Hobson (2002) calls for a "pedagogy of trust," characterized by care and challenge, the freedom to express the self (for both learner and teacher), an acceptance of the fragility of objectivity, and the willingness of instructors to 'put down their own power' in order that learners may pick it up and self-actualize their sense of authority. In this sense, 'trust is not simply a student's confidence in the teacher that the content of a programme is 'up to date' and that methods of assessment are 'fair' or 'valid'" (p. 268). Instead, it is about taking risks together and sharing what transpires. While risk is generally accepted within artistic performance contexts, performance-as-pedagogy requires more attentive consideration, particularly given the already-fraught spaces of contemporary undergraduate learning (Barnes et al., 2012; Denzin, 2015; Wilson \& Gerber, 2008).

Jennifer Sumner has argued that "eating is a pedagogical act" (2013, p. 47), a statement that riffs on and extends Wendell Berry's own powerful declaration that "eating is an agricultural act" (1990). Sumner also notes that eating is a social act and a cultural act, as well as a political, environmental, and economic act. It is as well, by its nature, a personal and embodied act. As an assemblage of these diverse 'acts,' eating and the processes that precede, follow, and surround it, take form as a cycle of entangled performances - of making, doing, thinking, feeling, and even being. A performance-based pedagogy thus suggests itself as a way to step into that cycle, and enable students to sense "a more wild patterning of the [food] 
world" (Szanto, 2018). It is a way to invite learning that is as systemic and hybrid as food systems themselves, "challenging existing gendered, geographic, sensory, and cultural hierarchies in the process" (Hunt, 2018, p. 29).

\section{Course structure}

"We can think of performance (1) as a work of imagination, as an object of study; (2) as a pragmatics of inquiry (both as model and method), as an optic and operator of research; (3) as a tactics of intervention, an alternative space of struggle."

—Dwight Conquergood (2002, p. 152)

Courses at Quest University are delivered through a "block system" in which students enrol in a single course per four-week period, each consisting of eighteen three-hour meetings. In addition, students are expected to complete three to five hours daily of readings, research, exercises, and/or assignments.

Performing With(in) Food was designed as a one-off course, open to all Quest students. It merged discursive, material, and processual learning, as well as occasions for oral and written reflection. Resources included literature on performance theory and practice, food studies, performativity and distributed agency, critical theory, and design. Videos and websites, featuring food art and performance documentation, rounded out the course material.

The course started with foundational questions about the linkages between food and performance, moving on to the evolution of performance and performativity, and the 'spectrum' of food performance, from artistic to environmental. Subsequent themes included material and linguistic agency, a queer perspective on failure and disruption, food politics, the process of iteration in shaping creative outputs, and tactical issues such as developing a performance score, dramaturgy and staging, and techniques related to performance documentation.

Our morning meetings brought together seminar-style discussions, review and analysis of performance and art works ${ }^{2}$, peer exchange, and reflexive exercises. Students were required to maintain a journal with entries on food and food issues, technical notes on performance, and themes for creative development. Each Monday, they submitted a written reflection, drawing on their journal notes, and cumulatively producing a sketch of their trajectory through the course.

\footnotetext{
2 Merging food, power, gender, technology, queerness, relationality, and other themes, these works included: Alison Knowles' "Identical Lunch"; Sandeep Bhagwati’s “Ecstasies of Influence”; Judy Chicago's "The Dinner Party"; food performances by Karen Finley and the Food Not Bombs collective's street-food actions; a range of examples cited in Barbara KirshenblattGimblett's "Playing to the Senses"; Simon Laroche \& David Szanto's “Orchestrer la perte/Perpetual Demotion”; Jana Sterbak's "Vanitas: Flesh Dress for an Albino Anorectic"; David Szanto's "The Gastronome In You”; Marije Vogelzang's "Eat Love Budapest”; and Dawn Weleski \& Jon Ruben's "Conflict Kitchen”. For additional examples and descriptions of past food performances, see: Kirshenblatt-Gimblett (1999) and Szanto (2017).
} 
Other weekly exercises included a peer-question-and-answer forum, bodywork practice (including sensory 'tuning,' breathing, physical-mechanical, and emotive-interactive exercises), the drafting and revision of a performance score (towards the showcase on the penultimate day), and on-campus, publicly witnessed group performances. These last were loosely framed by the group and then largely improvised; they included one processional performance, one exercise in Situationism, and one interventionist performance.

On the Monday of the fourth week, performance scores were 'finalized' and a schedule was negotiated for the showcase. Dramaturgy and blocking were (mostly) settled, including some partial rehearsals and documentation planning. For logistical reasons, one performance took place on the previous Sunday, while the remaining six spanned Tuesday. On the final Wednesday of the course, we debriefed and reviewed the seven performances and their documentation, including peer critique and commentary.

Some of what happened

"[Performance] is less 'a thing done' than a set of questions asked...the more it keeps on the slip, remains diffuse, and resists congealing...the greater service it provides...."

—Rebecca Schneider (2006, p. 253)

Accommodating a range of learning experiences, Performing With(in) Food was intended to engender knowledge that was both intellectual-discursive and embodied-affective. Based on previous teaching, I anticipated this might create cognitive or emotional disconnects, as well as occasions to bridge them through shared analysis and reflection. My desire was to allow emergent threads to arise and be explored, both collectively and individually. In what follows, I summarize several of these threads, including illustrations from the classes and performances.

\section{Building trust and worrying 'consent'}

Consent became an important theme during the first week of the course, as students articulated concerns about 'audience permission' within food performance contexts. These included the implications of bodily penetration, maintaining health and safety, confounding taste, and probing identity. Many flyers about sexual consent were posted across campus, and I suspected that this awareness had translated itself into questions of artistic consent. It was both striking and somewhat challenging regarding my ambitions for the course.

Early on, I expressed that food performance is a valuable means to blur and destabilize the 'boundary' between audiences and performers, and to trouble stable definitions of ethics, art, and social norms. My critical pleasure in this value was met by some students with 
consternation. Where is the line of consent? they wondered. What right do performers have to create risk for their audiences? Others recognized that consent is inherently given when an audience chooses to experience a performance, either by buying a ticket, stepping over a physical threshold, or remaining sensorially present. But what of interventionist performances, spontaneous actions in public, or other non-pre-framed actions? When a student in a library is suddenly confronted by a performance class trying out Situationism in the chairs around her, has she given consent to witness what happens? Did she do so merely by placing herself in a public setting? If so, what is not public and where might consent be implicitly withheld?

These questions - and the ways in which they relate to eating, consumer 'choice', and other public or private food activities - continued to inform undercurrents that were never fully resolved during the course. I kept uncertainty about them foregrounded while also working to ensure that whatever risk they presented was both visible and addressable. Two main exercises supported this, and while some students remained discomfited by trust, risk, and consent, the final performances also demonstrated a willingness to face - and engage with — that uncertainty.

\section{Performative iterations}

Each class thus began with the question, "How did you perform your food yesterday, and how did it perform you?" A bridging mechanism to establish continuity with the previous day's class and the students' work/play/leisure at home, the responses also allowed for additional food themes to be brought forward. Identity and upbringing, the agency of kitchens and supermarkets, hunger and decision-making, migration, love, death, and others were raised.

At the root of my question was a key issue: performance is both a thing we do and a thing that is done to us. Similarly, food and humans exist in a mutual relationship of co-production, just as food systems are both produced by and producers of humanity. The responses from students - generally four or five per class - gradually reflected their growing acceptance of these dynamics. Moreover, the additional themes that students raised helped inform the day's discussion and gave me cues for material and/or exercises that might be added to future meetings. In this sense, their thinking-doing with my daily question prompted my own improvisations while demonstrating my willingness to share in the risk of diverging from the syllabus.

The daily repetition of a question-and-answer cycle also served to reinforce two theoretical concepts and offer practical illustrations. Our readings on performativity addressed the ways in which repeated action tends to sediment itself into material and symbolic bodies. While the relevant texts (Austin, 1978; Miller, 2007; Searle, 1989) might have been read and appreciated during the previous afternoon's course prep, parsing the "stylized repetition of acts" (Butler, 1988, p. 519, original emphasis) that constitute day-to-day eating served to anchor a lived experience of performativity. 
The related concept of reiteration - central to performance-was also portrayed through our question-and-response ritual. While the wording of my inquiry remained the same, I altered my intonation and degree of whimsy or seriousness. By the end of the course, the question had been posed so many times that it was both reassuring and tedious, a matter of serious introspection, and our shared inside joke. Similarly, the students' responses became variously more insightful, impatient, reflexive, and straightforward. I understood this as a growing acceptance of the underlying point about intersubjectivity, and an embodiment of the question as both normal and provocative. On a more functional level, practicing reiteration helped students normalize the repetition of drafting and redrafting their performance scores. Rather than becoming an exercise in 'correcting' a draft, re-writing was understood as a process of discovery and emergence. The students' eventual performances and peer critiques seemed to reflect the creative value of iteration and its bodily and cognitive effects.

\section{Performing bodies}

A second set of exercises involved variations on the theme of 'body work,' in which physical action built connections between learning through words and deploying that learning through the body. Exercises included isometric practice, such as pushing hard against a wall or floor (borrowed from choreographer Twyla Tharp), and attentive breathing through alternate nostrils (borrowed from yogic practice). Each was preceded by my prompt to try to witness effects within the senses and emotions; a debrief and reflection session followed each exercise.

As a riff on Erving Goffman's The Presentation of Self in Everyday Life (1973), I and two student volunteers sequentially stood on a swivel chair while the rest of us attempted to 'read' the messages communicated by the person's appearance. While the exercise occasionally drifted into fashion critiques (particularly when I was on the chair), it also served to illustrate how gesture and aesthetic choices are part of the diurnal performance of being human. This tied neatly into parallels with daily food habits, as did the isometric and breathing exercises. Reflecting on the (dis)empowering sensations of struggling against an immovable object, or the stabilizing effects of breathing and remaining still, we drew easy analogies to food activism and resistance, including the capacities (and lack thereof) of an individual to bring about change within an apparently dominant system.

A classically inspired theatre exercise involved seating two students opposite one other, with the requirement that they not talk or laugh while maintaining eye contact. The rest of the group paid attention to body language, affective displays, and other cues about what the two might be experiencing. After approximately five minutes, I 'released' the students from their exercise, and we debriefed. A subsequent iteration involved me taking on the role of one of the sitters, while one student played timekeeper and another sat across from me. Channeling my inner Marina Abramović (2010), I attempted to project a wave of affect toward my partner. At a certain moment, I turned my palm upward and moved my forearm into the space between us, 
continuing to make eye contact. The student looked unsettled but intrigued. After some seconds, she reached forward and held my hand. We sat like that for perhaps another two minutes, and when the timekeeper eventually ended the exercise, I was hot, shaking, and red in the face. The student appeared equally moved.

In the debrief that followed these two exercises, students agreed that it is intensely challenging to both participate in and witness durational eye contact. My addition of hand contact also resurfaced the question of consent. Had the student across from me been coerced into taking my hand, because of student-teacher power dynamics? Was she pressured by the inherent requirements to participate in a classroom exercise on 'performance,' and therefore prompted to imagine a dramaturgy and take action? Or was it a matter of free will, creative intention, and experimentation?

While none of these questions was resolved - and certainly a good deal of emotional and affective discomfort remained — we had once again confronted a central question that relates to both food and performance. Direct, intense contact with 'the other' can threaten our sense of self, of personal security and bodily integrity. In the realm of food, the perceived threats within eating are mitigated through industrial and cultural control mechanisms such as cuisine, packaging, branding, and regulatory policies (Fischler, 1993). Yet these same devices have also been exploited over time, distancing us from the messiness of food production and mediating the ways in which we experience consumption (Atkins \& Bowler, 2001; Mansfield, 2003; Rousseau, 2012).

\section{Rigour, experimentation, and non-objectivity}

For the second of three on-campus experiments in public performance, we had collectively agreed to make a mini field trip to the central space of one of Quest's main buildings, where students often lounged, worked, chatted, and sat sipping coffee near a glassed-in fireplace. Earlier in the week, we had read two texts on the Situationist International (SI), an art-andpolitics movement that was active largely in the 1960s and which critiqued the mediation of social relations through commercialized objects (SI, n.d.) Our discussion of the SI had focused on their call for citizens to engage in artistic performance through the making of 'situations,' unstudied moments that might invert the dominant relationships among art, commerce, and spectacle. The SI readings coincided with our examination of John Cage's (1952) 'silent' piano performance, 4'33', and the insight it provides into the ways in which audiences perform just as much as do those 'on stage.'

We therefore decided to stage a 'situation' in the Atrium, seating our 15 bodies in a circle of chairs that faced outward from the center. We would then spectate upon those in the space, inverting the normative roles of performers and audience. When one of us felt so inclined, they would applaud or otherwise celebrate a 'performance' of someone around us. The experiment lasted about 20 minutes, and included the sharing of a bag of popcorn, leafing through mock playbills, miming gestures of appreciation, and some occasional whispered comments. At a 
certain moment, as agreed by the group in advance, one of us rose and initiated a standing ovation, in which the rest of us then joined. This brought an end to the exercise, and we returned to the classroom to debrief.

Another exercise the previous week had followed a similarly loose, experimental approach to public intervention, during which we created a relatively spontaneous, 'processional performance.' It wound through a number of spaces on campus and then also culminated at the Atrium Building, this time on the top floor. There we assembled around the open light well, looking down on the lounge area below. A series of rules regarding gesture and behaviour had been established in advance, including sound-making with a food-related object, improvised mimicry of others' movements, and an open-ended conclusion, which would ultimately be determined by whoever chose to trigger it.

Both exercises aimed less at copying precisely the historic indications for either processionals or situations, and more at establishing a comfort level with drawing attention, disrupting and/or engaging with public space, trusting in one's co-performers, and attending to their cues and prompts. My intention was partly to lay the foundations for our eventual performance showcase, both in terms of experimentation and self-confidence, and partly to synthesize some of the readings through embodied action in learning environments less normative than our classroom.

Our debriefs of the two performances, as well as comments in the course evaluation, revealed that these 'field trips' had been valuable in anchoring theoretic and historic examples of performance. As humans in chairs in a classroom, we learned by listening, speaking, and occasionally gesturing with a hand or shoulder. As humans rolling chairs across a snowy walkway, or climbing an indoor stairwell while rhythmically beating bowls with whisks, we learned to express abstraction through art. We also learned what it is to be witnessed by others, and just as passersby reflected on what we were doing, we reflected on them reflecting on us, creating the all-important relationality of performance. Within this 'feedback loop' of spectation, the students sensed the ways in which their own positionality plays out in creating a 'true interpretation' of what is happening. Truth was thus witnessed as pluralistic, given that we had to accept the co-existence of our own experience and our perception of the ways we appeared to others. The parallel for understanding food systems was front and centre: food 'realities' are multiple, produced through an interplay of discourses, materialities, and the performativity of language and substance.

At the same time, these exercises provided the students with a form of lived experience that both supported and offered critiques to the theoretic framings of processional performance and situationism that I had presented. For the former, we learned that processionals, though seemingly loosely organized, in fact require a strong degree of pre-planning, narrative, and commonly held rules. As social rituals, they are highly scripted, serving specific purposes such as celebration, mourning, transformation, and homeostasis (Schechner, 2003). To the viewer, they may appear spectacular, mundane, invitational, or exclusionary, yet each of these effects requires advance thinking and doing on the part of the performers. Given the evident role of food 
within rituals, the 'processional' cycles of growing seasons, and the ritual nature of transforming and eating food things, we found many points of connection to the matter of food.

In the case of creating situations, it became clear that the era in which the SI operated was key to the effectiveness of its social impact. Some sixty years later, flash mobs and other performative interventions are far more common, and have perhaps inured average citizens to the powerful critique that situationism originally presented. Moreover, as became clear in our own experiment, our outward facing chairs and 'stagey' presence was itself quite spectacular in the otherwise tranquil space of the Quest atrium. Inverted and re-inverted again, our performance was more a performative mimicry of situationism, rather than a situation in the SI's original intent. It had performed us just as much as we had performed it. While this reinforced the intersubjectivity of food and humans that the course addressed at the larger scale, it also revealed the ways in which attempting to invert systems-based power structures can fall flat or even backfire. Rather than suggesting the need for a "food revolution" (Petrini \& Padovani, 2006), the exercise helped reinforce the transformative value of iterative efforts and smaller steps towards food system change.

\section{Dissociations in and out of the classroom}

During the first week of classes, a reading that struck a powerful chord with many students was Barbara Kirshenblatt-Gimblett's "Playing to the Senses" (1999), a comprehensive historical survey of artistic performances that have treated food as both theme and medium. The author's interpretation of dissociation became the pivot around which we discussed her article: "While we eat to satisfy hunger and nourish our bodies, some of the most radical effects occur precisely when food is dissociated from eating and eating from nourishment. Such dissociations produce eating disorders, religious experiences, culinary feats, sensory epiphanies, and art” (p. 3). This notion resonated with several students, helping a realization to dawn about the ways in which food is normatively and often invisibly integrated with our lives. This then led to an understanding that there is value in 'de-normatizing' food through performance, precisely to re-sense its comforts and discomforts. Notably, the students extended their interpretation of dissociation to a variety of other themes in the course. It became an anchor point for discussions about body image and health, satiety in the absence of food, food as culture versus food as fuel, and cooking Korean, Japanese, or Balinese dishes in North America.

A concept related to dissociation is that of "perceptual multistability" (Fischer-Lichte, 2008, p. 88), that moment when audiences witness both 'actor' and 'character' coalesce into one state of existence while still perceiving them as separate. This condition can produce delight, confusion, dissonance, or even ecstatic transcendence among its witnesses. Historically, cooks have played with a version of perceptual multistability, creating trompe l'oeil dishes (e.g., fish formed in the shape of chicken) or architectural pièces montées (such as those of 19th-century French chef Marie-Antoine Carême). More contemporarily, the notion might be applied to plant- 
based and lab-grown 'meat,' as well as the playful yet tightly controlled dishes of avant-garde and molecular cuisine. Perceiving multistability has value beyond culinary theatrics, however. Sociopolitical and economic food issues, such as sovereignty and supply-chain management for example, might also be characterized by multistability, suggesting that training the mind and body to witness such a state can be useful across a range of food realities.

To explore multistability in our course, I proposed an in-class makeup exercise. Strongly anchored to the theatrical arts, applying makeup is a technique that supports an audience's perception of multiple realities. Feeling that enough trust had been established in our group to make the exercise feasible, I therefore invited the students to bring makeup with them to our 14th meeting, the last Thursday of our course, stating that I would do so as well. I nonetheless made it clear that it was fine not to participate.

As we sat around the table, a wide range of cosmetic resurfacing took place. I opted for full foundation coverage, heavy eyeliner, and beard and eyebrow pencil, in an attempt to 'erase' my normal appearance, even as I continued to play professor. Others drew flowers on cheekbones, applied glitter to foreheads, and painted lips with non-standard colors. One student simply highlighted her nose with pearlescent white eyeshadow, leaving the rest of her face bare. As the exercise had been scheduled toward the end of the class time, we then drifted off to the rest of our afternoons.

The following day, we debriefed the exercise, generally agreeing that, despite the safe environment of our classroom community, it had been strange and destabilizing to go 'out' looking as we did. One student noted that he was very conscious of being looked at by people at the recycling centre he had gone to that afternoon, a space he identified as highly masculinized. Though he had washed off the Amy Winehouse-like 'wings' at the corners of his eyes, traces of green glitter remained. As he purchased pieces of metal grating for his eventual performance installation, he had a strong sense of being seen in two ways. Others also noted that they had sensed themselves being differently perceived by friends and roommates, enhancing their identification as "students in that performance class" as well as bodies that soon would be performing again in public spaces on campus.

As we talked, it appeared that many in the group felt empowered by being able to articulate the embodied sensations they had felt through the theoretical understanding of the Fischer-Lichte and Kirshenblatt-Gimblett texts. As had happened in earlier conversations about the dissociative/reassociative nature of performance, a growing sense of the multiple, simultaneous nature of reality started to emerge, whether on a stage, in a classroom or kitchen, or around a conference table. Notably, although we had previously had an on-campus "disruptive performance" scheduled for Day 15, we collectively agreed that our makeup exercise had been adequately disruptive. Indeed, turning the disruption inward to our own sense of self may have been more pedagogically useful than staging an outward-facing intervention for others. 


\section{Reassociating food and performance(s)}

Located in the northeastern hills of Squamish, British Columbia, the Quest campus is relatively isolated. Most of the university's 800 students live in residence, and many, though not all of them, participate in the institutional meal plan. Residences have varying levels of kitchen infrastructure, and based on our in-class exchanges, it seemed that many of the students had a love-hate relationship with the Quest cafeteria, the Squamish dining and food-shopping options, and their domestic culinary opportunities.

One student, in particular, found the on-campus food to be a source of extreme frustration, indicating that when she had lived in residence, it made her feel imprisoned and disempowered. (At the time of our course, she had moved off campus and was cooking for herself.) Another noted that the quality of the food made it hard for her to want to eat, and that she had recently started smoking a small amount of pot on the way to the dining hall, to ensure that she had sufficient appetite. Many of the students had a range of overseas histories, and had thus acquired a taste and skill for international cuisine. While they seemed to take pleasure in their own meal-making, it was mitigated by the inconveniences of shopping and cooking that the Quest location and facilities implicated. In my own experience with the Quest cafeteria and café, I found them to be perfectly adequate, although I did imagine that were I to spend more than three and a half weeks on campus, I might align more closely with the students' attitudes.

It was from these very personal and day-to-day food experiences that several of the students' performance themes had emerged. They included food-as-sadness, food-ascollaboration, food-as-sensory-agent, and food-as-identity. One piece, "Banya," (see Table 1, below), was eventually developed around the dissociation of nourishment from edible food, and the potential for shared experience to create a sense of satiety, even in the absence of eating.

Already relatively grounded in critical thinking about normative dualities, the students nonetheless expressed the challenges of using language to express these problematics. For example, even as self and other were intellectually understood as either opposed (within dualistic thinking) or unified (within systems thinking), reading and saying "self" and "other" out loud reduced the tension between them. Yet as they began to interpret food as other through performance (and dissociative performances), many students began to sense the potential to embody a sense of their own 'otherness.' This appeared to be both liberating and confounding for them. The performativity of language, as expressed in academic texts, had started to translate into embodiment, and was therefore more holistically understood as well as more troubling. 
Some performances with food

"Because of the way it engages the senses, food offers particular challenges and opportunities for artists, both those interested in spectacular theatrical effects and those working on the line between art and life."

-Barbara Kirshenblatt-Gimblett (2012, p. 85)

The course culminated in a showcase of performances that were conceived, developed, and staged by the students. It served as an occasion to practice reiteration and reflexivity, a means to evaluate overall student learning, and an opportunity to share affective-environmental performance with the broader Quest community. In all, four performances were conceived individually (with collaboration from classmates in two cases) and three were based on an initial direction conceived by one person but collectively elaborated through a compressed cycle of iterative development.

Table 1: The Quest student performances

\begin{tabular}{|c|c|c|c|}
\hline performance & location/time & witnesses & concept and themes \\
\hline "Banya" & $\begin{array}{l}\text { riverbank (off campus); } \\
\text { Sunday AM/PM }\end{array}$ & $\begin{array}{l}\text { invited } \\
\text { guests }\end{array}$ & $\begin{array}{l}\text { a Russian-style outdoor steam bath, involving collaborative } \\
\text { construction, environmental immersion, endurance, } \\
\text { cleansing, and the induction of a feeling of nourishment }\end{array}$ \\
\hline "Seeds" & $\begin{array}{l}\text { central lawn (on } \\
\text { campus); Tuesday AM }\end{array}$ & passersby & $\begin{array}{l}\text { a solo, wordless performance, involving the extraction, } \\
\text { distribution, and planting of fruit seeds, the valorization of } \\
\text { life, and a critique of consumption }\end{array}$ \\
\hline $\begin{array}{l}\text { "Whisking } \\
\text { Together, } \\
\text { Whisking Apart, } \\
\text { Calling it Art" }\end{array}$ & $\begin{array}{l}\text { Atrium Bldg. stairwell } \\
\text { and café; Tuesday AM }\end{array}$ & $\begin{array}{l}\text { passersby; } \\
\text { café clients }\end{array}$ & $\begin{array}{l}\text { a multi-person, two-part processional and installation, } \\
\text { involving the whipping of cream, trust and risk, and } \\
\text { collective food production }\end{array}$ \\
\hline $\begin{array}{l}\text { "Strings } \\
\text { Attached" }\end{array}$ & $\begin{array}{l}\text { Academic Bldg. breakout } \\
\text { room; Tuesday AM }\end{array}$ & $\begin{array}{l}\text { course } \\
\text { enrollees }\end{array}$ & $\begin{array}{l}\text { a one-on-one relational storytelling experience, involving the } \\
\text { 'translation' of taste and emotion, intimacy, and trust }\end{array}$ \\
\hline $\begin{array}{l}\text { "A Destructive } \\
\text { Dinner Party" }\end{array}$ & $\begin{array}{l}\text { Cafeteria lobby; Tuesday } \\
\text { noon }\end{array}$ & $\begin{array}{l}\text { cafeteria } \\
\text { clients }\end{array}$ & $\begin{array}{l}\text { a staged, farcical performance of eating in public, involving } \\
\text { heightened visual cues, choreography, improvised messiness, } \\
\text { and a 'fancy' dinner outside a cafeteria }\end{array}$ \\
\hline $\begin{array}{l}\text { "Reflexive } \\
\text { Curry House" }\end{array}$ & $\begin{array}{l}\text { Academic Bldg. break- } \\
\text { out room; Tuesday PM }\end{array}$ & $\begin{array}{l}\text { invited } \\
\text { guests }\end{array}$ & $\begin{array}{l}\text { an immersive environment, involving visual and olfactory } \\
\text { cues, food consumption, reflective surfaces, introversion, and } \\
\text { an invitation to feel the (dis)comfort of eating alone }\end{array}$ \\
\hline $\begin{array}{l}\text { "Me, Myself, } \\
\text { and You" }\end{array}$ & $\begin{array}{l}\text { Academic Bldg. break- } \\
\text { out room / classroom; } \\
\text { Tuesday PM }\end{array}$ & $\begin{array}{l}\text { invited } \\
\text { guests }\end{array}$ & $\begin{array}{l}\text { a durational cooking performance involving vulnerability, } \\
\text { emotional self-doubt, and culinary confidence; the cooking } \\
\text { and serving of food to two isolated diners, each listening to } \\
\text { a recording of the cook telling 'secret' stories about herself }\end{array}$ \\
\hline
\end{tabular}


"Whisking Together," "Destructive Dinner," and "Curry House" all treated themes of collaboration and individuality in making and eating food, as well as distributing uncertainty and discomfort among a wide range of bodies in order to mitigate the associated risks. The performers of "Seeds" and "Me, Myself" both looked inward to the ways in which they personally value food, as well as the ways in which they perceived others value it. "Strings" related to the translations between taste and language, as well as the intimacy and vulnerability of sharing food, personal stories, and a physical connection. And "Banya" was an exercise in collectivity, as well as an attempt to re-perform a rite from the family heritage of the key instigator.

In what follows, I expand on three of these performances, drawing out what I view as key themes and their relationships to what the students had learned during our time together. For reasons of space, I do not address all seven of the pieces, though each represented multiple opportunities for analysis.

\section{Calling it art}

"Whisking Together" was staged in the glassed-in stairwell of the Quest Atrium Building. It combined processional performance, individual gestures to whip a bowl of cream, and a final, dramatic 'reveal' in which the conceiver of the piece lifted the bowl over her head and inverted it. Lasting approximately five minutes, the performance was visually delightful, gently fraught, and both showy and quotidian. The four-storey 'stage' established a distanciation between actors and audience, yet as I moved my own body closer to the glass wall, I became aware of a lively piece of music playing on the other side. For the performers, it was loud and engaging; for the audience, it was almost inaudible (unless they approached the stairwell). Because of this very difference, the work also portrayed the performativity of architecture - the membranes, boundaries, and channels that mediate sensory perception. 
Fig. 1: "Whisking Together, Whisking Apart, Calling it Art" (performers in the stairwell; inverting the bowl of cream; the Mason jar installation)
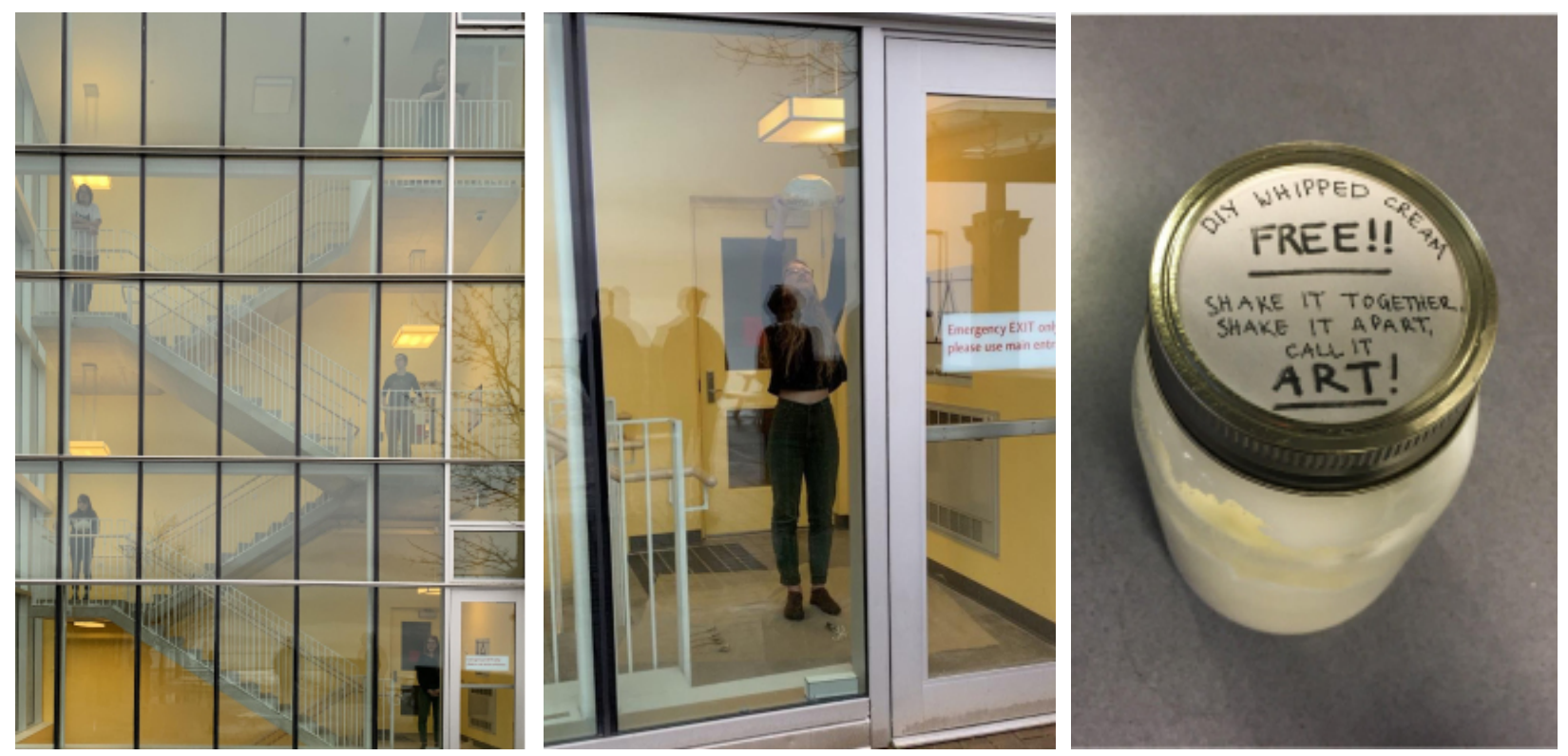

The performance had an 'annex' within the Atrium Building proper, taking place more passively for another audience. A second cream-whipping installation had been staged on a table near the small Quest café - a labelled Mason jar that invited 'non-performers' to collaboratively whip the cream inside by shaking the jar. Separated from a 'correct' script for whipping cream, however, and left to the efforts of 'untrained' actors, the Mason jar cream was transformed into butter, rather than fluffy peaks. The installation was intended to portray the ways in which end consumers are dependent on, and subject to, the performativities of food system actors that are often beyond our control and sometimes hidden from sight. As consumers, we accept the risks (and rewards) embedded in these relational webs, this part of the piece seemed to say. At the same time as demonstrating that unsupervised action can result in 'failure,' however, there was also the implication that such failure can be understood as a positive outcome. Butter isn't whipped cream, but it is still delicious.

"Seeds," too, took a multiple perspective on success and failure, value and waste. The conceiver and performer of the piece, strongly committed to agroecology and horticulture, wanted to communicate the critical yet under-valued function of seed saving within food systems. This performance also served to trouble the notion of beginnings and endings, in both natural lifecycles and cultural narratives.

Huddled under a protective overhang adjacent to the central lawn area, and directly in front of the windowed Quest administrative offices, our group stood uncertainly in the light drizzle. One student asked me when the performance was going to start; I indicated that it might already have done so and we should just wait and observe. Moments later, our solo artist leapt to his feet and with a howl slammed an apple he was holding onto the cement in front of him. It 
exploded, sending bits of peel and flesh along arcing trajectories. He did it again, and gestured that others might as well. Subsequent howls and apple-y eruptions ensued, drawing attention from Quest employees sitting at their office desks. Our performer then found and collected seeds from the detritus, cupping them preciously in his palm. The juicy pieces of apple flesh - the commoditized output of agriculture - were ignored. Each of us was offered a seed, and as I took one, I could feel heat emanating from the performer's hand. Most of the group followed the performer onto the snow-dotted grass in front of us, where they knelt and planted their seeds in the soil. I ate mine. Some of us drifted a bit aimlessly and the administrative staff returned their gazes to their computer screens. Eventually, the performance seemed to have stopped.

Like "Whisking Together," the seeds performance treated both the holism of food and food systems, as well as the individual relationships and agencies we all perform as consumereaters. What is valued or attended to by one of us may not be the same as that of others, but the set of dynamics we collectively enact constructs the system as a whole. What became evident to me - through the howling and drama, the attention/disinterest of the Quest employees, the diverse reactions of the rest of our group, and the porosity of the start-stop boundaries - was the challenges faced by those who try to intervene in food system normativities. That is, how can one both attract and maintain attention to the need for behavioural change and action? How can one person's passion activate that of multiple others? Where does one take such action, and when, given that the timeline of food is so fluid? And is it okay to disrupt things — and to waste edible food - if one's intentions are towards productive, longer-term change? Perhaps less outwardly explicit than "Whisking Together," "Seeds" seemed to demonstrate the student's very strong embodiment of these questions, and perhaps others. It was an effective, visceral expression of knowledge translation. 
Fig. 2: "Seeds" (crouching with apple debris; planting seeds)
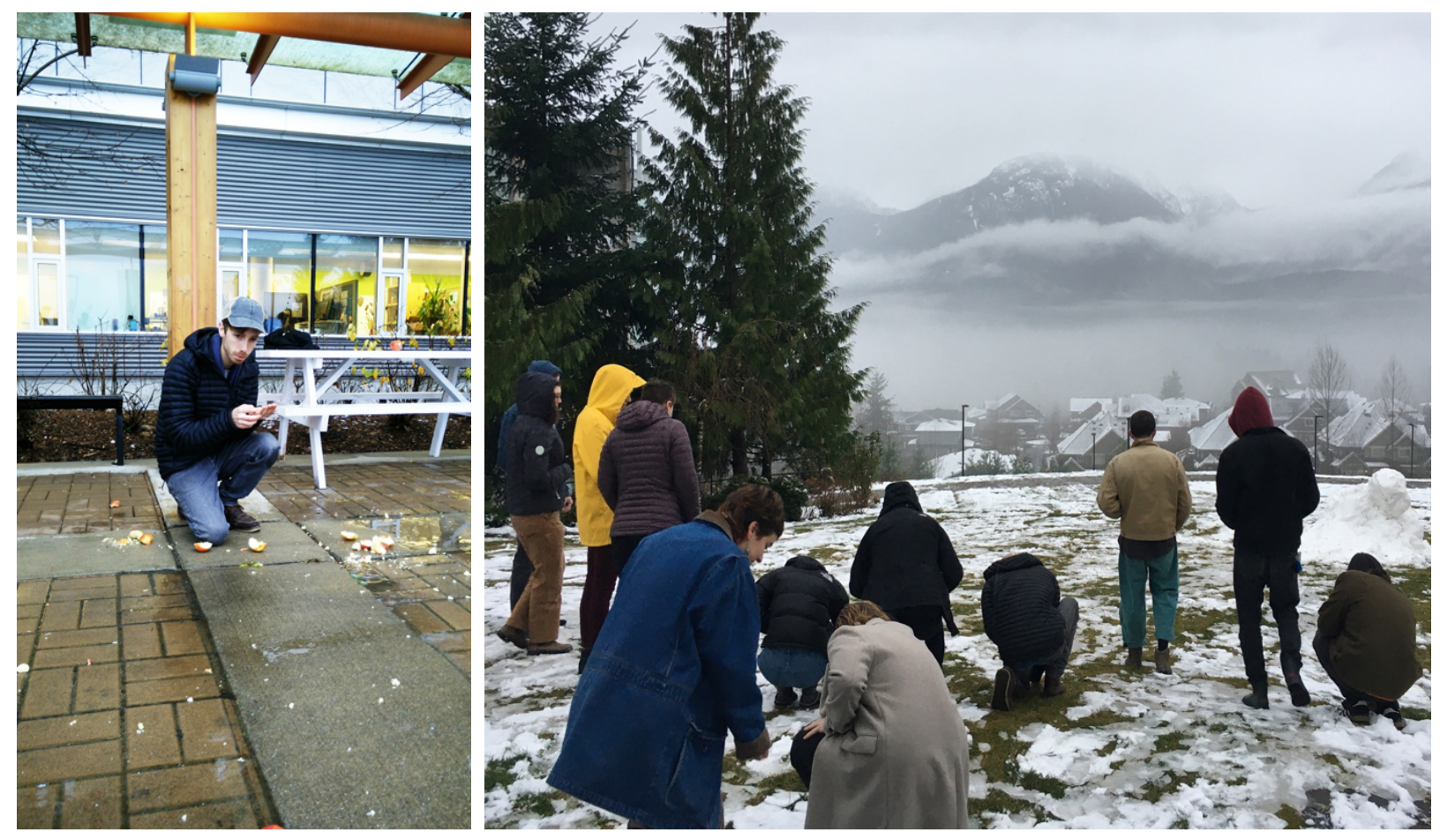

"Strings Attached" was staged in a small breakout room with a one-way mirror facing onto a second room. The one-on-one performance involved a seated performer and an array of multi-flavoured candies attached in pairs by a piece of string. We were invited to enter the room one at a time, sit down across from the performer, and choose a candy based on their labels: spicy, salty, numb, sweet, sour, and umami. Our choice was meant to reflect the 'taste' of a story we wanted to tell. Once settled in, the participant and the performer placed their respective candies in their own mouths, the string now forming a drapey connection between them. While allowing the candy to slowly dissolve, the 'audience' participant began to tell her story, and the performer mostly remained silent and listened.

Meanwhile, in the breakout room on the other side of the mirror, the rest of the class sat watching. Literally framed in this way, the performance was reduced to a visual experience not unlike watching an interview on a dim and fuzzy television with the sound off. The other sensory elements were blocked, and the strong sense of affect passing between the two string-connected participants was largely attenuated. For those watching, it was rather tedious, as the performer had given no prescriptions about the length of storytelling, nor how many storytellers he wanted to participate. As a consequence, many students drifted off once they had taken some notes and photos, played around with their own reflections, and muttered various comments. 
Fig. 3: "Strings Attached" (watching from behind the one-way mirror; the candy pairs, strung together)
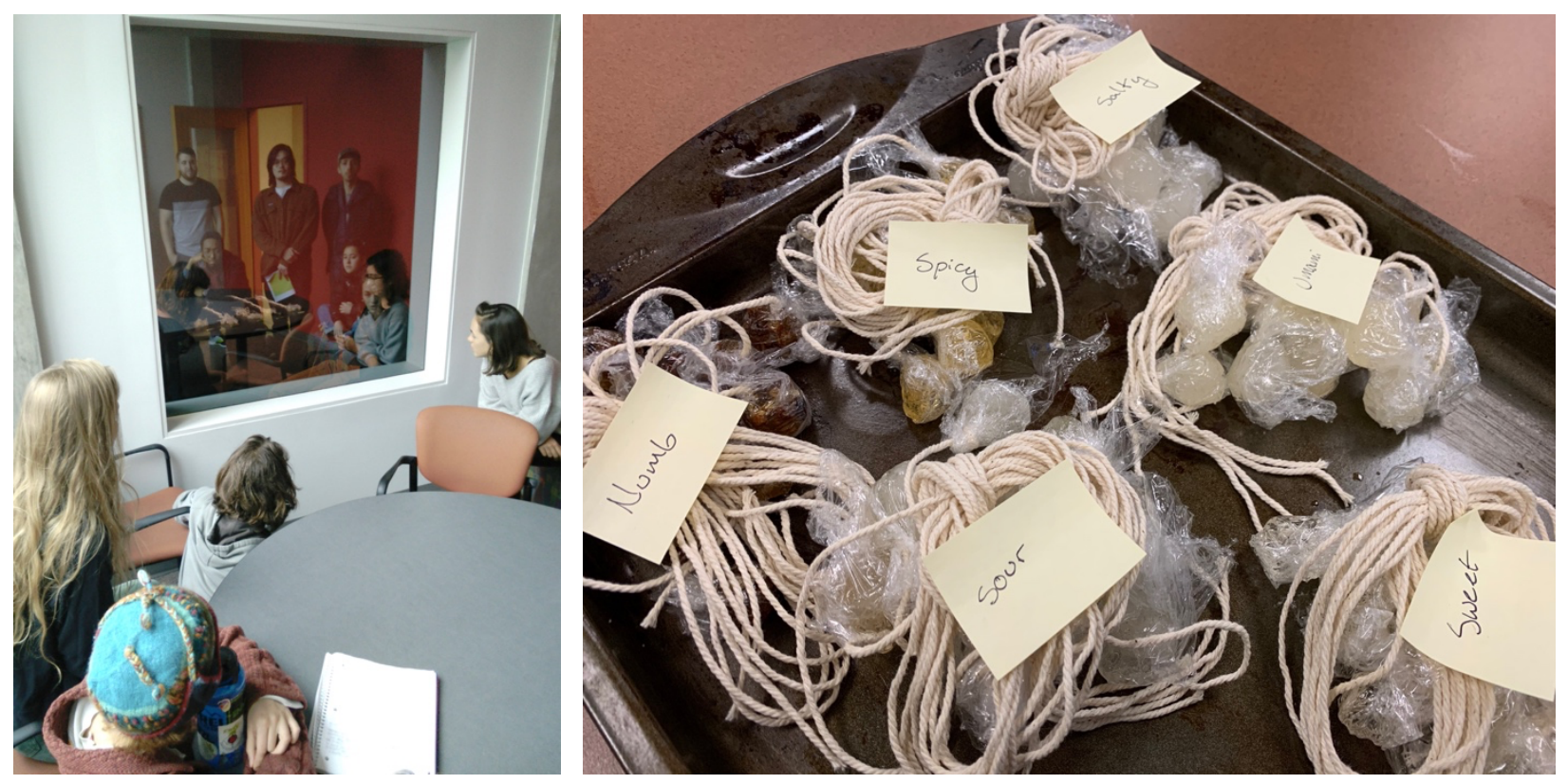

During my own turn as storyteller, I was very aware of the time constraints (in my role as teacher and facilitator), while also drawn into the intimacy and generosity of the moment. A subtle remix of inverting performance roles, 'translating' sensation into words and vice versa, and making one-on-one eye contact, "Strings" layered together many themes from our course content. It also demonstrated the challenges inherent to performance documentation, given that little happened that could readily be recorded in audiovisuals, and much of the experience was highly internal and affective. In this sense, it was a very successful demonstration of learning, yet like "Seeds," more internal than outwardly explicit.

\section{Digesting performance}

"To participate in a course about food and performance is to perform oneself and one's food, over and over again, every day, for as long that course endures. (And then afterward as well.)" -David Szanto (n.d., n.p.)

The above quotation appears in no previous publication; it is a recursive reflection that I wrote just now. It echoes and illustrates the very nature of performance, in which enactments may seem repeated or mimetic, but authentically exist in a singular time and place. As Kristin Hunt has noted, food performance "offers a rethinking of mimetic experience as not divorcing us from, but 
connecting us to the very faculties we must hone in order to learn, know, and tell the truth" (2018, p. 157). Such is the nature of food and food systems as well, and despite the rituals and seasons and harvests and cycles they comprise, they are always new in the moment of experience. Coming into resonance with those moments is what a pedagogy of performance can bring to food, and that is what I wished my Quest students to discover.

A key challenge for many is to find legitimacy in relational and reflexive learning, and for it to co-exist with the pedagogic norms of more science-based disciplines. Performing With(in) Food exposed some of these tensions. This was evidenced in course evaluation comments, including one that clearly articulated the student's own internalized bias towards physical sciences, as well as doubt about the scholarly efficacy of performance. Another expressed resistance towards some of the bodywork exercises, finding them ineffective as pedagogical tools and transgressive of classroom norms. A third noted that the focus on reiteration - including the use of several of my own texts about food and performance — was like "beating a dead horse."

Some students, however, acknowledged that performance had allowed them to both 'know' and 'sense' food-related issues, and for their intuitions, emotions, bodies, and aspirations to become part of the learning process. One noted that the readings "shockingly harmonized" with those from other courses in political economy, queer and feminist studies, and critical race theory. Another recalled Rebecca Schneider's notion of "the slip," noting that performance "fosters innovation, creativity, and new ideas within a system that has functioned the same way for hundreds of years."

As a private, secular, non-profit university set in the outdoorsy mecca of Squamish, Quest seems to attract a diverse and deeply motivated student body. The small class size and intensive schedule, the range of learning habits, and the students' immersion in the crossing of disciplines all made it possible for this course to achieve many of my intended results. Yet outside of this environment, can performance serve other food educators as a useful pedagogic framework?

Three factors suggest that the answer is yes. First, a pedagogy of performance is responsive, improvisational, and grounded - both in the classroom experience and the larger context of student and instructor lives. This requires trust to be established and risk to be accepted, a syllabus to guide but not limit teaching, and for discomfort and uncertainty to exist. Learning to accept instability may come through body techniques or reflexive discussion exercises, but it also depends on a willingness to experiment. Importantly, for the study of food systems, a sensitivity to complexity is needed, including non-linear learning paths.

Second, performance allows for numerous concepts and methods to be drawn from other disciplines, highlighting how different areas of scholarship can connect. Given that inter- and transdisciplinary approaches are increasingly used within food scholarship, performance offers a coherent space of practice. Parallels to theatrical, artistic, and domestic performances may also make food systems learning more personally relevant and provide a 'translation' tool among disciplines. 
A third reason for deploying performance in food pedagogy centres on the word with. As Donna Haraway has articulated (2016), with reminds us that bodies, minds, and feelings cooperate alongside one another, rather than relating hierarchically. It reinforces the mutual dependence and co-productivity of food and humans, place and culture, economics and politics, bodies and language. With is how learners and teachers can co-create knowledge in the classroom, and how students can collect facts and perspectives while also creating ethical stances towards future action. In the words of one Quest learner-performer, "What I walk away with is less what I've learned about performance and more what I've learned about the values from which performance emerges. I will carry these values into my upcoming academics."

Like the writer of those words, I too will carry forward what I have learned from Performing With(in) Food. I will remember to strut the line between art and academia with confidence, as well as with care and concern for others. I will forewarn students that not all will be comfortable, and that some exercises, readings, or assignments may not resonate with them. I will follow the lessons from my students' own performances, distributing risk, assuming personal responsibility, listening rather than talking, drawing and releasing attention, and not assuming shared values. Most of all, perhaps, I will valorize what seeds I can share, offering them freely, and accepting that others may or may not choose to plant and nurture them as I do.

Acknowledgements

I am grateful for the scholarly and community support of Carleton University's School of Journalism and Communication and Quest University Canada, including the students who took part in Performing With(in) Food. Particular thanks go to Irena Knezevic for her editorial insights, as well as the reviewers and editors who provided helpful feedback.

\section{References}

Abramović, M. (2010). The Artist is Present [Performance]. https://mai.art/long-durational-work Abrams, J. (2021). State of the Organization: Thoughts on the Importance of Theatre Education in 2020. Theatre Topics, 31(1), 1-4. https://doi.org/10.1353/tt.2021.0003

Akama, Y. (2015). Being awake to Ma: Designing in between-ness as a way of becoming with. CoDesign, 11(3-4), 262-274. https://doi.org/10.1080/15710882.2015.1081243

Alexander, B. K. (2006). Performance and Pedagogy. In J. A. Hamera \& S. Madison (Eds.), The SAGE Handbook of Performance Studies (pp. 253-260). Sage Publications. 
Atkins, P. J., \& Bowler, I. R. (2001). Food in Society: Economy, Culture, Geography. Arnold.

Austin, J. L. (1978). How to Do Things with Words. Harvard University Press.

Barnes, K. J., Smith, G. E., \& Constantine, M. (2012). You want me to trust you? Using adventure learning to teach millennials about trust. Organization Management Journal, 9(4), 255-267. https://doi.org/10.1080/15416518.2012.738532

Bennett, J. (2009). Vibrant Matter: A Political Ecology of Things. Duke University Press.

Berry, W. (1990). What Are People For? North Point Press.

Bradley, K., Gregory, M., Armstrong, J., Arthur, M., \& Porter, C. (2018). Graduate students bringing emotional rigor to the heart of community-university relations in food dignity. Journal of Agriculture, Food Systems, and Community Development 8(A), 221-236. https://doi.org/10.5304/jafscd.2018.08A.003

Butler, J. (1988). Performative acts and gender constitution: An essay in phenomenology and feminist theory. Theatre Journal, 40(4), 519-531.

Cage, J. (1952). 4'33" [Musical performance]. http://en.wikipedia.org/w/index.php?title=4\%E2\%80\%B233\%E2\%80\%B3\&oldid=593019627

Caines, R., \& Heble, A. (2014). The Improvisation Studies Reader: Spontaneous Acts. Routledge.

Carlson, M. (2004). Performance: A Critical Introduction. Routledge.

Conklin, J., Basadur, M., \& VanPatter, G. (2011). Rethinking wicked problems: Unpacking paradigms, bridging universes. NextD Journal, Conversation 28.

Conquergood, D. (2002). Performance studies: Interventions and radical research. TDR/The Drama Review, 46(2), 145-156. https://doi.org/10.1162/105420402320980550

Cook, T. (2009). The purpose of mess in action research: Building rigour though a messy turn. Educational Action Research, 17(2), 277-291. https://doi.org/10.1080/09650790902914241

Curzon-Hobson, A. (2002). A pedagogy of trust in higher learning. Teaching in Higher Education, 7(3), 265-276. https://doi.org/10.1080/13562510220144770

Denzin, N. K. (2003). Performance Ethnography: Critical Pedagogy and the Politics of Culture. SAGE.

Denzin, N. K. (2015). The politics and ethics of performance pedagogy. In N. K. Denzin \& M. D. Giardina (Eds.), Contesting Empire, Globalizing Dissent: Cultural Studies After 9/11 (np). Routledge. 
Evans, J., Davies, B., \& Rich, E. (2009). The body made flesh: Embodied learning and the corporeal device. British Journal of Sociology of Education, 30(4), 391-406. https://doi.org/10.1080/01425690902954588

Fischer-Lichte, E. (2008). The Transformative Power of Performance: A New Aesthetics. Routledge.

Fischler, C. (1993). L'Homnivore: Le goût, la cuisine et le corps. Odile Jacob.

Fischlin, D., \& Heble, A. (Eds.). (2004). The Other Side of Nowhere: Jazz, Improvisation, and Communities in Dialogue (1st ed). Wesleyan University Press.

Fischlin, D., \& Porter, E. (2017). Improvisation and global sites of difference: Ten parables verging on a theory. Critical Studies in Improvisation / Études Critiques En Improvisation, $11(1$ - 2). https://doi.org/10.21083/csieci.v11i1-2.3949

Folke, C. (2006). Resilience: The emergence of a perspective for social-ecological systems analyses. Global Environmental Change, 16(3), 253-267. https://doi.org/10.1016/j.gloenvcha.2006.04.002

Freire, P. (1996). Pedagogy of the Oppressed. Penguin Books.

Gloor, P. A. (2006). Swarm Creativity: Competitive Advantage Through Collaborative Innovation Networks. Oxford University Press.

Goffman, E. (1973). The Presentation of Self in Everyday Life. Overlook Press.

Gough, R. (Ed.). (1999). On Cooking. Routledge.

Guattari, F. (2008). The Three Ecologies. Continuum.

Hallam, E., \& Ingold, T. (2007). Creativity and Cultural Improvisation. Berg.

Haraway, D. J. (2016). Staying with the Trouble: Making Kin in the Chthulucene. Duke University Press.

Harrison-Pepper, S. (1999). Dramas of persuasion: Performance studies and interdisciplinary education. Theatre Topics, 9(2), 141-156. https://doi.org/10.1353/tt.1999.0012

Heldke, L. (2006). The unexamined meal is not worth eating. Food, Culture \& Society, 9(2), 201-219. https://doi.org/10.2752/155280106778606035

Heldke, L. (2018). It's chomping all the way down: Toward an ontology of the human individual. The Monist, 101(3), 247-260. https://doi.org/10.1093/monist/ony004

Hunt, K. (2018). Alimentary Performances: Mimesis, Theatricality, and Cuisine. Routledge. https://doi.org/10.4324/9780203704158 
Kirshenblatt-Gimblett, B. (1999). Playing to the senses: Food as a performance medium. Performance Research: On Cooking, 4(1), 1-30.

Kirshenblatt-Gimblett, B. (2012). Making sense of food in performance: The table and the stage. In S. Banes \& A. Lepecki (Eds.), The Senses in Performance. Routledge.

Korsmeyer, C., \& Sutton, D. (2011). The sensory experience of food. Food, Culture \& Society, 14(4), 461-475. https://doi.org/10.2752/175174411X13046092851316

Latour, B. (2005). Reassembling the Social: An Introduction to Actor-Network-Theory. Oxford University Press.

Latour, B. (2013). An Inquiry into Modes of Existence. Harvard University Press.

Law, J. (2004). After Method: Mess in Social Science Research. Routledge.

Loxley, J. (2007). Performativity. Routledge.

Lupton, D. (1996). Food, the Body and the Self. Sage.

Mansfield, B. (2003). 'Imitation crab' and the material culture of commodity production. Cultural Geographies, 10(2), 176-195. https://doi.org/10.1191/1474474003eu261oa

McRae, C., \& Huber, A. (2017). Creating Performances for Teaching and Learning: A Practice Session for Pedagogy. Springer.

Miller, J. H. (2007). Performativity as performance / performativity as speech act: Derrida's special theory of performativity. South Atlantic Quarterly, 106(2), 219-235. https://doi.org/10.1215/00382876-2006-022

Morton, T. (2007). Ecology without nature: Rethinking environmental aesthetics. Harvard University Press.

Nguyen, D. J., \& Larson, J. B. (2015). Don't forget about the body: Exploring the curricular possibilities of embodied pedagogy. Innovative Higher Education, 40(4), 331-344. https://doi.org/10.1007/s10755-015-9319-6

Orr, D. W. (2004). The Nature of Design: Ecology, Culture, and Human Intention. Oxford University Press.

Pearson, M. (2006). In Comes I: Performance, memory and landscape. University of Exeter Press.

Perullo, N. (2016). Taste as Experience: The Philosophy and Aesthetics of Food. Columbia University Press. 
Petrini, C., \& Padovani, G. (2006). Slow Food Revolution: A New Culture for Dining \& Living. Rizzoli.

Phillips, J. (2006). Agencement/assemblage. Theory, Culture \& Society, 23(2-3), 108-109.

Pineau, E. L. (1995). Re-casting rehearsal: Making a case for production as research. Journal of the Illinois Speech and Theatre Association, 46, 43-52.

Rousseau, S. (2012). Food Media: Celebrity Chefs and the Politics of Everyday Interference. Bloomsbury Academic.

Sawyer, R. K. (1999). Improvisation. Journal of Linguistic Anthropology, 9(1/2), 121-123.

Sawyer, R. K. (2004). Creative teaching: Collaborative discussion as disciplined improvisation. Educational Researcher, 33(2), 12-20.

Schechner, R. (2003). Performance Theory. Routledge.

Schneider, R. (2006). Intermediality, infelicity, and scholarship on the slip. Theatre Survey, 47(02), 253-260. https://doi.org/10.1017/S0040557406000238

Searle, J. R. (1989). How performatives work. Linguistics and Philosophy, 12(5), 535-558.

Settee, P., \& Shukla, S. (2020). Indigenous Food Systems: Concepts, Cases, and Conversations. Canadian Scholars.

SI. (n.d.). Situationist International Archive. Situationist International Online. Retrieved June 23, 2020, from https://www.cddc.vt.edu/sionline/si/situ.html

Stephens, P., \& Hinton, L. (2021). The state of post-secondary food studies pedagogy in Canada: An exploration of philosophical and normative underpinnings. Canadian Food Studies, 8(3), 298-325.

Stolz, S. A. (2015). Embodied learning. Educational Philosophy and Theory, 47(5), 474-487. https://doi.org/10.1080/00131857.2013.879694

Sumner, J. (2013). Eating as if it really matters: Teaching the pedagogy of food in the age of globalization. Brock Education Journal, 22(2). https://doi.org/10.26522/brocked.v22i2.341

Sweetser, E. (2001). Blended spaces and performativity. Cognitive Linguistics, 11(3-4), 305-

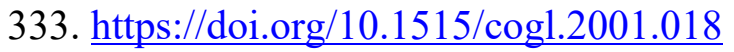

Szanto, D. (2017). Performing with(in) food. In P. Naccarato \& K. LeBesco (Eds.), The Bloomsbury Handbook of Food and Popular Culture (pp. 226 - 242). Bloomsbury Academic.

Szanto, D. (2018). Blurred, broken, and bewildered: What performing with food does with the lines around performance and food studies. In/Tensions, 9.0. 
Wilson, M., \& Gerber, L. E. (2008). How generational theory can improve teaching: strategies for working with the "millennials." Currents in Teaching and Learning, 1(1), 2-44.

Wilson, S. (2009). Research Is Ceremony: Indigenous Research Methods. Fernwood Publishing. 